\title{
Projeto codIFic@r: Oficinas de Programação em Dispositivos Móveis no Ensino Fundamental
}

\author{
Rudieri Dietrich Bauer ${ }^{1}$, Gian Luca Motta Flores ${ }^{1}$, Ângelo Nery Vieira Crestani ${ }^{1}$, \\ Jaline Gonçalves Mombach ${ }^{1}$ \\ ${ }^{1}$ Instituto Federal de Educação, Ciência e Tecnologia Farroupilha \\ RS-377, Km 27 - Passo Novo - CEP 97555-000 - Alegrete - RS \\ \{rudierib, gianlucamottaflores, angelovieira.c\}@gmail.com \\ jaline.mombach@iffarroupilha.edu.br
}

\begin{abstract}
Most of the researchers describe benefits of programming teaching in primary schools. However, most Brazilian schools do not offer this knowledge regularly. Therefore, this paper reports the experience while an extension project for teaching programming for teenagers. Computational Thinking, Collaborative Practices, and Problem-Based Learning using the MIT App Inventor platform were used was used as a methodology.The preliminary evaluations indicate that practice presents satisfactory results and could be offered to other schools and cities to enhance the development of logical thinking and interest in the computational area.
\end{abstract}

Resumo. A maioria dos pesquisadores descrevem os benefícios do ensino de programação em escolas primárias. Mas, muitas escolas brasileiras não oferecem esse conhecimento regularmente. Então, este artigo reporta a experiência em um projeto de extensão para ensino de programação à adolescentes. Pensamento Computacional, Práticas Colaborativas e Aprendizagem Baseada em Problemas usando a plataforma MIT App Inventor, foram usadas como metodologia. As avaliações preliminares indicam que a prática apresenta resultados satisfatórios e pode ser oferecida para outras escolas e cidades para melhorar o desenvolvimento do raciocínio lógico e interesse na área computacional.

\section{Introdução}

O pensamento computacional consiste na união de fundamentos e conceitos da Ciência da Computação com o pensamento crítico, utilizando técnicas e metodologias presentes dessa área. Wing (2006) descreve diferentes abordagens, entre elas, o ensino de programação nas escolas. Atualmente, o acesso a este conhecimento não está popularizado nas instituições brasileiras, principalmente nas cidades interioranas. Percebe-se que o contato regular dos jovens com programação é restrito somente aos cursos de informática, seja nível técnico ou superior.

O alto índice de evasão de alunos da área de informática também é um fator preocupante. Rebouças et al. (2010) destacam que a falta de conhecimento sobre o meio, acarreta em desinteresse e frustração com os cursos, principalmente nas disciplinas iniciais de programação, o que consequentemente ocasiona na desistência de vários estudantes. Tal fato acaba por gerar a deficiência de profissionais de tecnologia qualificados, principalmente quando comparado à demanda de mão-de-obra. 
VI Congresso Brasileiro de Informática na Educação (CBIE 2017)

Anais dos Workshops do VI Congresso Brasileiro de Informática na Educação (WCBIE 2017)

Além disso, uma pesquisa do Instituto Brasileiro de Geografia e Estatística (2016) mostra que houve um aumento de 147,2\% no número de usuários de telefone móvel celular na última década. Em 2015, aproximadamente 139,1 milhões de pessoas com 10 anos ou mais de idade possuíam um dispositivo móvel, ou seja, 78,3\% da população do país . Logo, as escolas não podem ignorar a presença desse aparelho nas salas de aula e uma das formas de inclusão de uso no plano pedagógico pode ser por meio da criação de aplicativos móveis pelos próprios alunos.

Portanto, este artigo relata a experiência de um projeto de extensão que tem como objetivo oferecer oficinas para ensino de programação em dispositivos móveis nas escolas públicas, salientando a viabilidade da utilização de smartphones em sala de aula. A estratégia usa a ferramenta App Inventor (Massachusetts Institute of Technology, 2017) para facilitar a aprendizagem e consequentemente, atrair mais jovens para a área computacional.

O restante deste trabalho está organizado como segue. Na Seção 2, apresentamse conceitos relacionados ao ensino de programação e pensamento computacional nas escolas. Tendo visto isso, a Seção 3 descreve as metodologias que vieram a ser aplicadas neste projeto. A Seção 4 é reservada ao relato das experiências das atividades realizadas. Por fim, na Seção 5, são discorridas as avaliações finais do projeto e a Seção 6 apresenta as considerações finais.

\section{Computação nas Escolas}

Wing (2006) defende que o ensino de programação nas escolas não beneficia somente os jovens que apresentam interesse pela área, visto que a computação é aplicada em diferentes contextos, e transcender o domínio de mero expectador para tornar-se colaborador pode ser um expressivo diferencial na sociedade do conhecimento.

Nesse mesmo sentido, a Sociedade Brasileira de Computação (2017) incentiva o ensino do pensamento computacional desde a educação básica, já que evolui consideravelmente a capacidade de dedução e conclusão de problemas (COSTA et al., 2016). Recentemente, a SBC elaborou um documento que propõe referenciais de formação em computação para a educação básica, tendo como eixos norteadores o Pensamento Computacional, o Mundo Digital e a Cultura Digital. Nesse documento o ensino de programação surge como uma das atividades essenciais para desenvolver habilidades de resolução de problemas e a fluência no mundo digital .

Atualmente, o ensino de programação está presente na educação básica somente em grades curriculares de cursos técnicos integrados e/ou subsequentes. Porém, o ensino de programação em escolas de nível fundamental é um tema já abordado em diversos trabalhos. Oliveira et al. (2014), por exemplo, descrevem um projeto de extensão realizado com finalidade de lecionar sobre conceitos básicos de computação no ensino fundamental.

Scaico et al. (2012), relatam a introdução da ciência da computação para alunos do $5^{\circ}$ ao $9^{\circ}$ ano, utilizando atividades desplugadas. A proposta não utiliza computadores e tem como base situações que envolvam trabalho em equipe, resolução de problemas e incentivo à criatividade dos discentes. Como resultados, os autores salientam que foi possível um levantamento de quais atividades eram mais adequadas para cada faixa etária.

Segundo Zilli et al. (2004), a robótica computacional, por abranger diretamente a 
programação, potencializa áreas como concepção lógica e senso matemático. Ademais, o empenho em pesquisas, a capacidade crítica e resolução de problemas são proveitos também citados pelo autor. Já Pereira e Siqueira (2016) destacam que no método educacional atual, os estudantes apenas recebem informações sem explorar seu desenvolvimento intelectual e capacitivo para resolução de problemas. A introdução do pensamento computacional, presente na programação, pode ser considerada uma estratégia para o desenvolvimento do ensino básico, dando oportunidade aos discentes de explorarem o raciocínio lógico-matemático e a resolução de problemas de forma efetiva.

Dessa forma, observa-se que as atividades de ensino de programação nas escolas públicas de nível fundamental são, em maioria, ações isoladas, realizadas por Instituições de Ensino Superior em propostas de extensão.

\subsection{Smartphones na Sala de Aula}

Com a crescente expansão da utilização de smartphones, os resultados relatados em Instituto Brasileiro de Geografia e Estatística (2016), apontam uma porcentagem de 74,0\% de estudantes os quais possuíam aparelhos telefônicos móveis para a utilização pessoal no ano de 2015, número que vem a crescer ano após ano. Com isso, trabalhos como o de Mateus e Brito (2011) apresentam pesquisas voltadas à busca por formas de utilizar-se da presença cada vez mais constante de celulares e smartphones em sala de aula, a fim de contribuir no processo de aprendizagem dos alunos.

Visto a evolução tecnológica dos últimos anos é possível adaptar metodologias de ensino e agregar tecnologias móveis para as salas de aula contemporâneas. Liu et al. (2009) reconhecem que os dispositivos móveis oferecem mais do que apenas aumentar recursos de ensino, agregam importância e possibilidades à educação fazendo da computação móvel um potencializador de ensino em diversos ambientes.

O uso de plataformas como o MIT App Inventor podem contribuir para o aprimoramento da utilização conjunta de smartphones durante os horários letivos, principalmente em cursos voltados para a área da computação, em que os discentes têm a possibilidade de desenvolver aplicações para seus próprios aparelhos e testá-los simultaneamente, como demonstrado em Finizola et al. (2014).

Dessa forma, o presente projeto aliou a necessidade de incluir os smartphones como ferramentas de ensino nas salas de aula regulares à importância do ensino de programação na educação básica. A seção a seguir descreve as metodologias utilizadas ao decorrer do projeto.

\section{Metodologia}

A metodologia empregada reúne conceitos do Pensamento Computacional, assim como a realização de atividades com Aprendizagem Baseada em Problemas (ABP) e Práticas Colaborativas. Segundo Andrade et al. (2013), pensamento computacional é um processo de raciocínio que se origina da combinação do pensamento crítico com os fundamentos da computação envolvido na formulação de problemas e das suas soluções, estando diretamente vinculada à Aprendizagem Baseada em Problemas.

\subsection{Aprendizagem Baseada em Problemas}

A aprendizagem baseada em problemas, do inglês Problem-Based Learning (PBL), é uma metodologia educacional que enfatiza a colaboração e o trabalho em grupo ao realizar 
a resolução de um problema, fazendo uso de ocasiões do mundo real e estudos de caso hipotéticos como maneira de melhorar a eficácia no processo de aprendizagem (FONTES; NETO; PONTES, 2011).

Costa et al. (2007) falam que a PBL parte através da premissa de um problema real sendo implantado de maneira que para sua solução seja necessária a explicação do conjunto de ações que levaram à ele, permitindo assim que os aprendizes desenvolvam o conhecimento de forma autônoma, sem a necessidade de um controle total por parte do tutor. Assim, viabiliza-se uma forma de aprendizagem mais natural e variada, tendo em vista que diferentes formas de resolução podem vir a serem usadas na solução de um problema.

\subsection{Ferramentas Utilizadas}

Diferentes ferramentas já vêm sendo utilizadas como catalizadoras no processo de ensino de programação em escolas, dentre estas se destacam as que possuem maior apelo visual, bem como facilidade de ensinamento e uso do conceito de blocos de códigos para a resolução de problemas. Durante esta iniciativa optou-se pelo uso das seguintes ferramentas: Blockly Games ${ }^{1}$, Estúdio Code.Org ${ }^{2}$ e em especial, a utilização do MIT App Inventor ${ }^{3}$.

O Blockly Games e o Estúdio Code.Org apresentam interface intuitiva para iniciação à lógica de programação e objetivos similares. Porém, o Blockly Games é disponibilizado também em versão off-line, o que facilita o uso em escolas sem conexão à internet. O Estúdio Code.Org, por sua vez, contém uma série de atividades com personagens populares do público infantil, agregando quebra-cabeças e desafios lógicos a enredos já conhecidos.

O MIT App Inventor é uma plataforma educacional on-line que permite o desenvolvimento de aplicativos móveis para o sistema Android com conceitos de programação em blocos. Por meio desta ferramenta é possível modificar a interface gráfica das aplicações, explorando diversos recursos, como sensores (acelerômetro, proximidade, localização, giroscópio, etc.) e notificações, assim como conectar-se a banco de dados, enviar mensagens, e-mails e realizar chamadas. Também, permite que sejam criados aplicativos de forma facilitada, pois os alunos instalam e testam suas criações em seus próprios dispositivos ou em emuladores Android (Massachusetts Institute of Technology, 2017).

\section{Relato de Experiência}

O presente artigo descreve a primeira edição do projeto codIFic @r, realizado em 2016 na cidade de Manoel Viana, Rio Grande do Sul. Destaca-se que o Projeto Codificar teve continuidade e atualmente está na segunda edição, com proposta ampliada para três cidades, e parceria com outra Instituição de Ensino Superior.

O primeiro planejamento do projeto visou a instrução das oficinas no laboratório do IFFar, com intuito de incentivar a aproximação dos alunos com o meio de ensino

\footnotetext{
${ }^{1}$ Disponível em https://blockly-games.appspot.com/

${ }^{2}$ Disponível em https://studio.code.org/

${ }^{3}$ Disponível em http://appinventor.mit.edu/explore/
} 
VI Congresso Brasileiro de Informática na Educação (CBIE 2017)

Anais dos Workshops do VI Congresso Brasileiro de Informática na Educação (WCBIE 2017)

técnico e superior, oportunizando também conhecer as instalações escolares. Tendo em vista tal propósito, foi elaborado um edital de inscrições para escolas públicas da cidade de Alegrete, deixando em aberto a participação de qualquer instituição de ensino da rede pública.

Após a disponibilização do edital houve prazo para as escolas se inscreverem, porém, obteve-se o retorno de apenas uma escola. Deduz-se que o ocorrido deu-se pelo fato das escolas desconhecerem as atividades que seriam executadas e também por deveras distância do centro urbano ao Campus do Instituto Federal Farroupilha (IFFar), aproximadamente trinta e cinco quilômetros.

Sem o retorno esperado, a estratégia foi alterada, passando a adotar abordagem direta com as escolas. Com o intuito de projeto piloto, entrou-se em contato com a Estadual de Ensino Fundamental Salgado Filho, da cidade de Manoel Viana, município próximo ao Campus. Após reunião com a direção escolar foi decidido que as oficinas seriam ministradas no laboratório da própria escola, dado que os computadores presentes estavam ociosos.

Ao observar o ambiente e número limitado de computadores, criaram-se duas turmas em contraturno, nas quais alunos da tarde realizaram atividades de manhã e viceversa. As turmas foram formadas por 15 alunos do $5^{\circ}$ ao $9^{\circ}$ ano do ensino fundamental, escolhidos pela direção da Escola. A limitação de vagas foi devido número de máquinas disponíveis no laboratório. O grupo executor do projeto era composto por oito professores e sete alunos voluntários do Tecnólogo em Análise e Desenvolvimento de Sistemas. Os encontros semanais tinham duração de três horas e ocorreram de outubro a dezembro de 2016.

O laboratório da Escola utilizava o sistema Linux Educacional e como a conexão com a internet não suportaria todos os alunos conectados simultaneamente, foi criado um servidor local para uso da plataforma off-line. Para o decorrer das aulas ministradas, elaborou-se um roteiro de cada encontro, sendo apresentado seu resumo de atividades na Tabela 1.

Tabela 1. Sumarização das atividades planejadas para os encontros.

\begin{tabular}{cl} 
Encontro & \multicolumn{1}{c}{ Ações } \\
\hline 1 & $\begin{array}{l}\text { Apresentação do grupo, introdução ao conceito de programação e exploração } \\
\text { dos desafios do Blockly e Code.Org }\end{array}$ \\
\hline 2 & $\begin{array}{l}\text { Criação de e-mail (somente alunos acima de 13 anos) e investigação inicial na } \\
\text { ferramenta MIT App Inventor }\end{array}$ \\
\hline 3 & $\begin{array}{l}\text { Descoberta de aplicativos compartilhado na galeria e introdução ao conceito de } \\
\text { operadores e estruturas de seleção com jogo da memória }\end{array}$ \\
\hline 4 & $\begin{array}{l}\text { Exploração dos elementos de entrada de dados e criação de aplicativos com } \\
\text { alertas, caixas de texto, trocas de tela e uso de sensores }\end{array}$ \\
\hline 5 & Resolução de problemas (Cálculo de IMC, Média entre notas, Quiz) \\
\hline 7 & Desenvolvimento de jogos (Pedra, Papel e Tesoura / Espaçonave) \\
\hline
\end{tabular}


VI Congresso Brasileiro de Informática na Educação (CBIE 2017)

Anais dos Workshops do VI Congresso Brasileiro de Informática na Educação (WCBIE 2017)

\subsection{Primeiro e Segundo Encontros}

O primeiro encontro teve por objetivo a apresentação dos discentes ministrantes e dos alunos participantes, além de descrever o Projeto codIFic@r e seu propósito. Para aproximação foi feita uma roda de conversa, em que cada pessoa declarou seu nome, idade, ano que estudava, o que esperava do curso, qual seu nível de conhecimento em informática e o nível de utilização de aplicativos em celulares. Após as devidas apresentações foi mostrado vídeos de motivação do movimento Code.Org, no qual celebridades mundiais relatam a relevância do ensino de programação e pensamento computacional nas escolas e como o desenvolvimento de software pode mudar o mundo.

Os alunos do turno da tarde, pela conexão de internet instável, exploraram jogos educacionais do Blockly, que buscam o ensino do pensamento lógico, já no turno da manhã além destes jogos foi aproveitado os desafios da página on-line do Code.Org. Ressalta-se que neste primeiro encontro as turmas obtiveram seu primeiro contato com comandos básicos presentes na programação de software, como estruturas de seleção e repetição e operadores matemáticos básicos.

No segundo encontro apresentou-se a plataforma a ser usada durante o projeto, o MIT App Inventor. Para mostrar a capacidade da plataforma demonstraram-se as facilitações da programação em blocos e aplicativos contidos na sua biblioteca, evidenciando as possibilidades de criação. Os discentes ministrantes do projeto explanaram sobre as ferramentas da plataforma utilizada, a parte visual (design do aplicativo) e a parte lógica (blocos de código).

Durante esse encontro criaram-se aplicativos de código simples, mas que demonstrassem os conceitos básicos da programação, como aplicações de entrada e saída com textos e operações matemáticas básicas de adição e subtração. Após explicação passo a passo, os participantes sempre eram desafiados a melhorar o protótipo desenvolvido. Inicialmente, deveriam acrescentar as operações de multiplicação e divisão, por exemplo. Essa tarefa de passo a passo era importante, pois observou-se certa insegurança nos participantes para exploração autônoma da ferramenta. Logo, a abordagem PBL era aplicada após tutorial inicial, quando os alunos recebiam desafios sobre o tema apresentado.

Notou-se que a turma da tarde conseguiu se aprofundar mais na plataforma e seus conceitos matemáticos, visto que obtiveram sucesso ao receberem a tarefa de criar um programa que calculasse duas médias de alunos e retornasse se eles estariam aprovados ou não, adotando estruturas de seleção nos protótipos. A turma da manhã teve maiores dificuldades e acredita-se que devido ao mau tempo, visto que as chuvas atrapalhavam o deslocamento dos alunos e com isso alguns faltavam aos encontros, sendo indispensável relembrar os conceitos a cada aula.

\subsection{Terceiro e Quarto Encontros}

O terceiro encontro iniciou-se com a teoria de operadores matemáticos de comparação e seleção. Para maior dinamismo, foi realizado uma atividade de jogo da memória com os operadores, visto que com as turmas mistas, diversos alunos desconheciam símbolos de maior, menor, diferente, potenciação e etc. Inicialmente, todos os operadores foram apresentados e depois um aluno era sorteado para responder qual era o operador exibido. A Figura 1 apresenta o jogo da memória criado que foi explorado de forma conjunta com o grupo. 

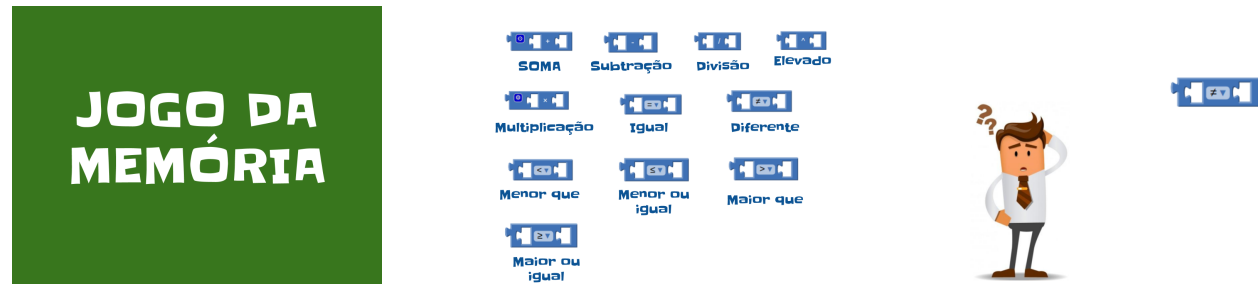

Figura 1. Registro do jogo da memória.

Posteriormente, a turma foi desafiada a resolver cálculos de precedência de operadores também. Com a monitoria, os discentes foram instruídos a criar um aplicativo de comparação de algarismos, informando qual o maior e qual o menor.

Além disso, os alunos tiveram o desafio de melhorar o aplicativo de cálculo de médias feito anteriormente, devendo informar se com a nota retornada seria aprovado, reprovado ou estaria em recuperação. Para finalizar a aula foi proposto a criação de um aplicativo para calcular o Índice de Massa Corporal (IMC) a partir da inserção de dados do usuário, classificando-o em abaixo do peso ideal, no peso ideal, acima do peso ideal e obeso.

A partir do quarto encontro as atividades propostas foram totalmente práticas, uma vez que os alunos já haviam se familiarizado e adquirido conhecimentos suficientes para a realização destas. Durante esse encontro foram dadas orientações para a escolha de tema para um Game Quiz, tal jogo deveria conter trocas de telas e outros assuntos abordados durante as aulas. Os jogos foram feitos com as mais variadas temáticas e os participantes foram orientados, à medida que fossem terminando seu quiz, para auxiliar os colegas. Percebe-se que tal atividade, com prática colaborativa, engaja a turma e também ajudava a suprir as dificuldades de alguns alunos.

O quinto encontro tratou-se de uma revisão do conteúdo visto até o momento e a resolução de novos desafios, como a criação do jogo pedra, papel e tesoura e o jogo "Pong"na plataforma, que utiliza elementos de animação e sprites. Após essa contextualização foi revelada a proposta do último encontro, a criação de um aplicativo para concurso.

\subsection{Concurso Melhor App}

Com o objetivo de incentivar os participantes para a criação de aplicativos próprios, a partir de sua criatividade, elaborou-se um concurso. Nesse concurso cada aluno que desejasse participar deveria criar um aplicativo, apresentá-lo na visita ao Campus, espaço onde seria realizada votação.

Dessa forma, os dois últimos encontros foram dedicados à criação dos aplicativos do concurso. Os três melhores aplicativos receberiam prêmios de acordo com primeiro, segundo e terceiro lugar. A equipe orientadora ficou a cargo de observar e auxiliar os discentes no desenvolvimento da aplicação, sendo que poderiam pedir auxílio aos instrutores e colegas, caso necessário.

O último encontro ocorreu no IFFar, tendo as duas turmas participantes do projeto e outras turmas de $5^{\circ}$ a $9^{\circ}$ ano da Escola, levadas até o Campus por meio de um ônibus disponibilizado pela própria Instituição. A mostra dos aplicativos criados foi apreciada 
VI Congresso Brasileiro de Informática na Educação (CBIE 2017)

Anais dos Workshops do VI Congresso Brasileiro de Informática na Educação (WCBIE 2017)

por toda a comunidade escolar. Nas apresentações eram encontradas releituras de jogos clássicos, aplicativos para desenho e também quizzes com temas alinhados à sala de aula (Geografia, Matemática, etc). Após a finalização do concurso, os alunos foram convidados a realizar um passeio pela Instituição, a fim de conhecer as instalações e apresentar os cursos oferecidos. A Figura 2 exibe os alunos apresentando os aplicativos criados.

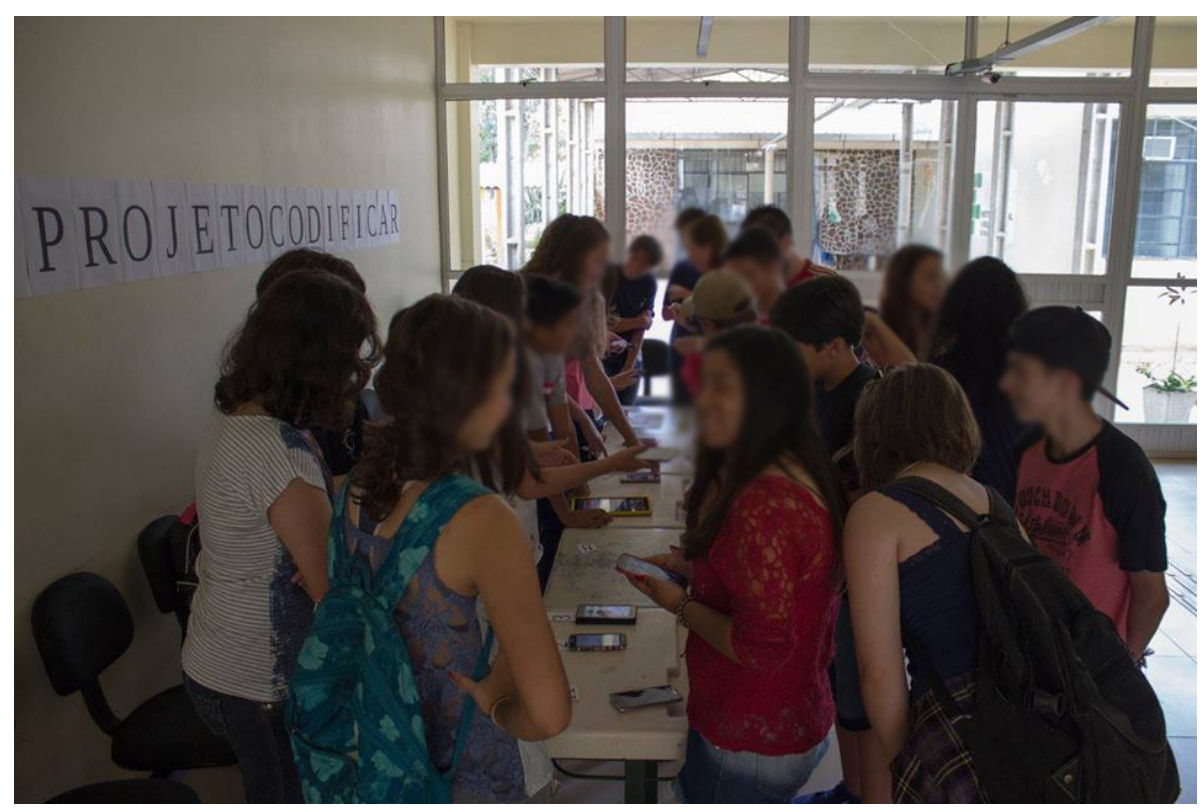

Figura 2. Foto da apresentação de aplicativos.

Por fim, os participantes responderam a um questionário para avaliação da atividade realizada, descrito na próxima Seção.

\section{Avaliação dos Participantes}

Com o final da primeira edição do projeto, foram desenvolvidos dois diferentes questionários sendo um aplicado aos alunos participantes do projeto e outro à equipe executora. A partir de uma escala com cinco pontos, os participantes avaliaram a equipe executora e as atividades desenvolvidas. Também, de forma qualitativa eram questionados sobre o que mais gostaram no projeto e o que poderia ser melhorado.

Após a análise dos questionários constata-se que o projeto obteve um resultado positivo, visto que puderam ser observados fatores como o interesse pela área por parte dos participantes e maior divulgação das ações realizadas na Instituição. Exemplificam-se como relatos dos alunos: "levaram o trabalho a sério, foram atividades complicadinhas, mas as primeiras aulas foram com conteúdo simples, fizemos vários projetos apesar de ter sido poucas aulas", "legais e divertidas fáceis de compreender", "Porque os professores conseguiram ensinar a programação para leigos, eu gostei muito da maneira como eles conseguiram explicar o conteúdo de uma maneira engraçada e envolvente", "porque eles souberam ensinar, nao dão aquela aula chata, sabem o momento sério e o momento de dar uma conversada, aprendi muito, sabem muito bem ensinar a programar, explicam duas vezes se necessário, não deixam os alunos com nenhuma dúvida”.

A equipe executora ressaltou como deficiência e consequentemente, limitação ao projeto, a precariedade do laboratório de informática da Escola, visto que em diversas 
ocasiões eram necessárias interrupções em meio aos encontros para a reinicialização dos computadores, reconexões com a plataforma após quedas de rede e periféricos que ocasionalmente apresentavam problemas de funcionamento. Porém, a experiência aos acadêmicos e professores foi avaliada como satisfatória, já que a comunicação com a comunidade externa permite a análise de diversas demandas para até mesmo a criação de outros projetos de extensão.

\section{Considerações Finais}

Este artigo relatou a experiência de um projeto de extensão com trinta alunos de turmas mistas, entre $5^{\circ}$ e $9^{\circ}$ anos do Ensino Fundamental. No projeto, realizaram-se oficinas com o App Inventor para a criação de aplicativos móveis pelos participantes.

A metodologia, baseada no Pensamento Computacional, engloba desafios para resolução em grupo e também um concurso final para promoção de criatividade, coautoria e autonomia aos alunos. As limitações descritas são quanto aos equipamentos do laboratório de informática da escola.

A comunidade escolar, assim como o corpo diretivo da escola participante do projeto avaliaram de forma positiva a ação uma vez que se pôde observar resultados como o ingresso de alunos participantes do projeto em cursos técnicos a nível médio oferecidos pelo IFFar no ano seguinte. Dessa forma, além da exploração do pensamento computacional nas escolas, o projeto propiciou a divulgação dos cursos de Informática e consequentemente o interesse de mais jovens pela área.

O Projeto Codificar atualmente está em sua segunda edição, contemplando novas escolas e outras cidades da região. Também, ressalta-se a alteração de determinados membros da equipe executora por questões externas, dando oportunidade a novos participantes e a parceria com alunos de cursos de Licenciatura, tal como o curso de Licenciatura em Matemática.

\section{Referências}

ANDRADE, D. et al. Proposta de atividades para o desenvolvimento do pensamento computacional no ensino fundamental. In: Anais do Workshop de Informática na Escola. [S.1.: s.n.], 2013. v. 1, n. 1, p. 169.

COSTA, I. C. et al. Desenvolvimento de um curso seguindo a aprendizagem baseada em problemas: um estudo de caso. In: Anais do Workshop de Informática na Escola. [S.1.: s.n.], 2007. v. 1, n. 1.

COSTA, T. et al. A importância da computação para alunos do ensino fundamental: Ações, possibilidades e benefícios. In: Anais do Workshop de Informática na Escola. [S.1.: s.n.], 2016. v. 22, n. 1, p. 593.

FINIZOLA, A. B. et al. O ensino de programação para dispositivos móveis utilizando o mit-app inventor com alunos do ensino médio. In: Anais do Workshop de Informática na Escola. [S.1.: s.n.], 2014. v. 20, n. 1, p. 337.

FONTES, L. M. d. O.; NETO, F. M. M.; PONTES, A. Á. A. Ontopbl: Uma ontologia de domínio sobre aprendizagem baseada em problema. In: Brazilian Symposium on 
VI Congresso Brasileiro de Informática na Educação (CBIE 2017)

Anais dos Workshops do VI Congresso Brasileiro de Informática na Educação (WCBIE 2017)

Computers in Education (Simpósio Brasileiro de Informática na Educação-SBIE). [S.1.: s.n.], 2011. v. 1, n. 1 .

Instituto Brasileiro de Geografia e Estatística. Acesso à Internet e à televisão e posse de telefone móvel celular para uso pessoal, 2015: Pesquisa Nacional por Amostra de Domicílios. IBGE, Instituto Brasileiro de Geografia e Estatística, 2016. Disponível em: $\langle$ https://books.google.com.br/books?id=S3LtAQAACAAJ $\rangle$.

LIU, T.-C. et al. The effects of mobile natural-science learning based on the $5 \mathrm{e}$ learning cycle: A case study. Journal of Educational Technology \& Society, JSTOR, v. 12, n. 4, p. 344, 2009.

Massachusetts Institute of Technology. App Inventor. 2017. Disponível em: $\langle$ http://appinventor.mit.edu/explore/〉.

MATEUS, M. de C.; BRITO, G. da S. Celulares, smartphones e tablets na sala de aula: complicações ou contribuições? In: X Congresso Nacional em Educação-Educere. [S.1.: s.n.], 2011. v. 10.

OLIVEIRA, M. L. S. de et al. Ensino de lógica de programação no ensino fundamental utilizando o scratch: um relato de experiência. In: XXXIV Congresso da SBC-XXII Workshop de Ensino de Computação, Brasília. [S.1.: s.n.], 2014.

PEREIRA, L. C.; SIQUEIRA, S. W. M. Programe-se: O pensamento computacional na educação básica. 2016.

REBOUÇAS, A. D. D. S. et al. Aprendendo a ensinar programação combinando jogos e python. In: Brazilian Symposium on Computers in Education (Simpósio Brasileiro de Informática na Educação-SBIE). [S.1.: s.n.], 2010. v. 1, n. 1.

SCAICO, P. D. et al. Um relato de experiências de estagiários da licenciatura em computaçao com o ensino de computaçao para crianças. Revista Novas TecnologiasRENOTE, v. 10, n. 3, 2012.

Sociedade Brasileira de Computação. Referenciais de Formação em Computação: Educação Básica. 2017. Disponível em: 〈http://www.sbc.org.br/files/ ComputacaoEducacaoBasica-versaofinal-julho2017.pdf $\rangle$.

WING, J. M. Computational thinking. Communications of the ACM, v. 49, n. 3, p. 33-35, 2006.

ZILLI, S. d. R. et al. A robótica educacional no ensino fundamental: perspectivas e prática. Florianópolis, SC, 2004. 